\title{
Microencapsulation of ergosterol and Agaricus bisporus L. extracts by complex coacervation using whey protein and chitosan: Optimization study using response surface methodology
}

\author{
Adenilson Renato Rudke ${ }^{\mathrm{a}, \mathrm{b}, \mathrm{c}}$, Sandrina A. Heleno ${ }^{\mathrm{a}, \mathrm{b}}$, Isabel P. Fernandes ${ }^{\mathrm{a}, \mathrm{b}}$, M.A. Prieto ${ }^{\mathrm{a}, \mathrm{d}}$, \\ Odinei Hess Gonçalves ${ }^{c}$, Alírio E. Rodrigues ${ }^{\mathrm{e}}$, Isabel C.F.R. Ferreira ${ }^{\mathrm{a}, * *}$, \\ Maria Filomena Barreiro ${ }^{\mathrm{a}, \mathrm{b}, *}$ \\ ${ }^{a}$ Centro de Investigação de Montanha (CIMO), Instituto Politécnico de Bragança, Campus de Santa Apolónia, 5300-253, Bragança, Portugal \\ ${ }^{\mathrm{b}}$ Laboratory of Separation and Reaction Engineering - Laboratory of Catalysis and Materials (LSRE-LCM), Polytechnic Institute of Bragança, Campus Santa Apolónia, \\ 1134, 5301-857, Bragança, Portugal \\ c Programa de Pós-Graduação em Tecnologia de Alimentos (PPGTA), Universidade Tecnológica Federal do Paraná, Campus Campo Mourão (UTFPR-CM), via Rosalina \\ Maria dos Santos, 1233, CEP 87301-899, Caixa Postal: 271, Campo Mourão, PR, Brazil \\ ${ }^{\mathrm{d}}$ Nutrition and Bromatology Group, Faculty of Food Science and Technology, University of Vigo, Ourense Campus, E32004, Ourense, Spain \\ ${ }^{\mathrm{e}}$ Laboratory of Separation and Reaction Engineering-Laboratory of Catalysis and Materials (LSRE-LCM), Faculdade de Engenharia, Universidade do Porto, Rua Dr. \\ Roberto Frias s/n, 4200-465, Porto, Portugal
}

\section{A R T I C L E I N F O}

\section{Keywords:}

Microencapsulation

Whey protein/chitosan coacervates

Wastes valorization

Agaricus bisporus L.

Ergosterol

Response surface methodology

\begin{abstract}
A B S T R A C T
In the present work microencapsulation was applied to an ergosterol enriched extract (EEE) from Agaricus bisporus L. and pure ergosterol (PE) using a complex coacervation process. The process was optimized following two steps: (i) using response surface methodology to optimize the conditions of temperature $\left(T, 55\right.$ to $\left.95^{\circ} \mathrm{C}\right)$, protein-to-chitosan ratio $(P / C, 0.5$ to 10.5$)$, maximizing yield $\left(Y_{1}, \%, \mathrm{w} / \mathrm{w}\right)$, efficiency $\left(Y_{2}, \%\right.$, w/w) and load $\left(Y_{3}, \%, \mathrm{w} / \mathrm{w}\right)$; and (ii) using the dose-response methodology to optimize the ergosterol content $(E)$ at the optimal conditions achieved in (i). The global optimal conditions for both cases were the same ( $T$ of $55{ }^{\circ} \mathrm{C}$ and a $P / C$ of 0.5 ), but with maximized responses of $Y_{1}=75.02 \% ; Y_{2}=100.00 \%, \quad Y_{3}=12.78 \%$, and $Y_{1}=19.19 \%$; $Y_{2}=100.00 \%, Y_{3}=15.87 \%$, respectively. The effect of increasing ergosterol content led to the reduction of the microencapsulation yield, but with an increase in the ergosterol load and maintenance of the microencapsulation efficiency.
\end{abstract}

\section{Introduction}

Agaricus bisporus L. is a mushroom extensively consumed worldwide in many different cultures (Rúbia Carvalho Gomes Corrêa, Brugnari, Bracht, Peralta, \& Ferreira, 2016), representing a share of about 3.9 millions of tons of the global mushroom industrial production ("A detailed analysis of the recombination landscape of the button mushroom Agaricus bisporus var. bisporus," n.d.). A. bisporus is cultivated in more than 70 countries, being appreciated for its sensory characteristics and health benefits (Liu, Jia, Kan, \& Jin, 2013). It is a rich source of mycosterols, namely ergosterol (5,7,22-ergostatrien-3 $\beta$-ol), which represents about $90 \%$ of its sterol fraction (Barreira, Oliveira, \& Ferreira, 2014). Ergosterol, and its peroxidation products are known as compounds of strong bioactivity exhibiting antioxidant, anti-inflammatory and antitumor properties (Barreira \& Ferreira, 2015). Ergosterol can act similarly to phytosterols in reducing cholesterol levels (Gil-ramírez, Ruiz-rodríguez, Marín, Reglero, \& Soler-rivas, 2014), encouraging its use as a functional agent in the food industry (Heleno et al., 2017, pp. 103-110).

Although Agaricus bisporus L. presents a high concentration of ergosterol (Heleno et al., 2016), the low solubility of its free form, in both lipophilic and hydrophilic systems, limits its bioavailability (Rúbia C.G. Corrêa, Peralta, Bracht, \& Ferreira, 2017). To circumvent these constraints, different techniques have been used to facilitate its use in different matrices.

The microencapsulation technique can be a solution to assure the protection of ergosterol against external agents and can also improve both the solubility and bioavailability of ergosterol. In this technique a

\footnotetext{
* Corresponding author. Centro de Investigação de Montanha (CIMO), Instituto Politécnico de Bragança, Campus de Santa Apolónia, 5300-253, Bragança, Portugal.

** Corresponding author.

E-mail addresses: iferreira@ipb.pt (I.C.F.R. Ferreira), barreiro@ipb.pt (M.F. Barreiro).
} 
substance such as a bioactive compound, regardless of its physical state, is protected by a shell or included in a matrix material (Corredig, 2009, p. 738; Gaonkar, Vasisht, Khare, \& Sobel, 2014; Kwak, 2014). This process is being increasingly used in the food industry (Corredig, 2009, p. 738) assuring protection against the surrounding media, avoiding chemical degradation, and increasing stability and bioavailability (Dias, Ferreira, \& Barreiro, 2015). Among the used microencapsulation techniques in the food industry, extrusion, freeze drying, spray drying and coacervation can be cited (Edris, Kalemba, Adamiec, \& Piaotkowski, 2016), as well as the electrospray (Sayed et al., 2018), co-axial spraying (Rasekh et al., 2017), microfluidics (Nisisako, 2016) and systems using $\mathrm{CO}_{2}$ as the supercritical fluid (Getachew \& Chun, 2016). Concerning the coacervation process (CP), it is one of the most widely used microencapsulation techniques, providing high encapsulation loads and suitable releasing properties (Ifeduba \& Akoh, 2016). Generally, CP is classified in simple CP where only one hydrocolloid is used, or complex, which requires the interaction of two oppositely charged hydrocolloids (Anema \& Kruif, 2016; Sutaphanit \& Chitprasert, 2014). The used shell materials may be obtained from a wide range of synthetic and natural polymers, and, their selection depends on the active principle to be encapsulated, and on the final product specifications (Sánchez, García, Calvo, Bernalte, \& González-gómez, 2016). Furthermore, in the case of food applications, these materials must be classified as Generally Recognized As Safe (GRAS) (Gaonkar et al., 2014; Nedovic, Kalusevic, Manojlovic, Levic, \& Bugarski, 2011).

In complex $\mathrm{CP}$, process that finds a wide utilization (Elmer, Karaca, Low, \& Nickerson, 2011), the most used encapsulation materials are proteins and polysaccharides (Sanchez, Mekhloufi, \& Renard, 2006). Among them, chitosan (C), obtained from deacetylation of chitin (Kurukji, Norton, \& Spyropoulos, 2014), the second most abundant polysaccharide in nature (Lian, Pan, \& Wang, 2016), has been widely applied (Kurukji et al., 2014). Also, whey protein isolates (P) from dairy industry waste, whose main representative constituent is the $\beta$-lactoglobulin group, has been also extensively explored (Ach et al., 2015; Wee et al., 2014; Yu, Liu, Zhu, \& Kong, 2012). From an environmental point of view, the use of whey protein is an attractive strategy to valorize the current excess of this residual material. Considering chitosan, the whey protein is an oppositely charged hydrocolloid constituting an adequate chemical system to be used in complex $\mathrm{CP}$, able to entrap hydrophobic bioactive compounds, improving their resistance to thermal denaturation, and of high interest for specific food process systems (Corredig, 2009, p. 738).

Microencapsulation through complex CP using chitosan and whey protein is influenced by the physicochemical characteristics of both components, the composition of the used chemical system, namely the bioactive to be encapsulated, and process conditions such as $\mathrm{pH}$, protein/chitosan ratio, temperature and bioactive content, (Gulão, Souza, Fernanda, Coimbra, \& Garcia-rojas, 2014).

The microencapsulation process using WPI and chitosan, namely the size of the obtained microparticles, can be controlled by changing the stirring rate, $\mathrm{pH}$ and the WPI/chitosan ratio (Ahmed, Aschi, \& Nicolai, 2018). These wall materials have been already used to microencapsulate phytosterols, giving rise to uniform microcapsules with an average size of less than $25 \mu \mathrm{m}$ (Tolve et al., 2018), and to microencapsulate cashew juice, being effective in protecting the sensitive compounds of this food matrix (D. D. S. Bastos, Gonçalves, Andrade, Araújo, \& Rocha Leão, 2012). Concerning the specific topic of ergosterol microencapsulation, there are already in literature works dealing with the encapsulation of pure ergosterol (Zhang et al., 2016) and ergosterol-rich extracts (Francisco et al., 2018). Furthermore, it is known that WPI/chitosan systems have already been used efficiently with other active principles (D. S. Bastos et al., 2010; Tavares \& Noreña, 2019). However, to the best of our knowledge, no studies concerning the encapsulation of ergosterol-rich extracts, or pure ergosterol, have been performed using WPI/chitosan systems.

Currently, the application of mathematical models such as the response surface methodology (RSM) is increasingly used to optimize complex systems and is gaining a wide acceptance among the scientific community (Pinela et al., 2016; Pinela et al., 2016). It allows the simultaneous optimization of a number of variables while taking into account the complex interactions among them. RSM is also important in the prediction of the responses maximization (Ferreira et al., 2007).

In this perspective, the aim of this study was to optimize the microencapsulation of ergosterol (either in pure form or as a constituent of a $A$. bisporus extract) by complex $\mathrm{CP}$ using chitosan and whey protein coacervates as the encapsulation materials. The RSM was used to optimize the process considering as responses the microencapsulation yield $(\%, w / w)$, efficiency $(\%, w / w)$ and load $(\%, w / w)$. From this study, it is expected to achieve the following targets: 1) optimize the conditions of the complex $\mathrm{CP}$ by maximizing the defined response criteria; and 2) develop, at laboratorial scale, a consistent process for ergosterol microencapsulation highlighting its potential to support a future industrial application.

\section{Materials and methods}

\subsection{Standards and reagents}

Methanol and acetonitrile (HPLC grade) were used from Fisher Scientific (Lisbon, Portugal). The sterol standards (ergosterol and cholecalciferol) were purchased from Sigma (St. Louis, MO, USA). Whey protein isolate (P, purity on dry basis higher than $92 \%$ ), commercially available as Provon 295, was provided from Glanbia Nutritionals (Kilkenny, Ireland). The low molecular weight chitosan (C, tradename Chitosan 90/200/A1), with a deacetylation degree of 93.1\%, was purchased from BioLog-Heppe (Landsberg, Germany). Water was treated with a Milli-Q water purification system (TGI pure water systems, Greenville, SC). All other chemicals and solvents were of analytical grade and purchased from Portuguese suppliers.

\subsection{Source A. bisporus material and extraction procedure}

Samples of Agaricus bisporus L. were provided by a local mushroom producer "Mogaricus mushrooms - Sociedade Unipessoal Ltda", and classified as biowastes by this company. They correspond to specimens with non-conformities to be commercialized. Samples were weighed, frozen, freeze-dried (Freezone 4.5 freeze dryer model 7750031, Labconco, Kansas City, MO, USA) and reduced to powder form (20 mesh) for further use.

Ergosterol enriched extracts were obtained using an ultrasound-assisted extraction (UAE) apparatus QSonica model Cl-334 (Newtown, CT, USA) according to previous reported optimized conditions ( $375 \mathrm{~W}$ and $15 \mathrm{~min}$ ) (Heleno et al., 2016). Briefly, $3 \mathrm{~g}$ A. bisporus sample were weighed and mixed with $100 \mathrm{~mL}$ of ethanol. After the required extraction time, samples were centrifuged, filtered (Whatman $n^{\circ} 4$ filters) and the supernatant subjected to evaporation under reduced pressure. The content of ergosterol on the obtained extracts was $36.72 \pm 0.01 \mathrm{mg} / \mathrm{g}$.

\subsection{Microencapsulation procedure}

Microencapsulation was conducted using the obtained ergosterol enriched extracts (EEE) and the pure ergosterol (PE) itself, used as a control of the microencapsulation process for comparative purposes. The complex CP was applied according to the procedure described by Kurukji et al. (2014) with some modifications. Briefly, the process started with the preparation of a C solution ( $1 \%$, w/v) using an acetate buffer $(100 \mathrm{mM})$ with the desired $\mathrm{pH}$. The solution was left under stirring overnight at $55{ }^{\circ} \mathrm{C}$ to guarantee the complete dissolution. Thereafter, EEE or PE, was dissolved at the required concentration in a sodium acetate buffer $(100 \mathrm{mM}$ with the same $\mathrm{pH}$ of the chitosan solution was used) using an Ultra-Turrax (Unidrive X100 homogenizer 
(Ingenieurbüro CAT, Germany))) for $20 \mathrm{~min}$. Thereafter, $\mathrm{P}$ was added at the needed amount. Solutions were prepared in order to achieve the required EEE or PE concentration and the protein-to-chitosan ratio $(P /$ $C$ ) by mixing $5 \mathrm{~mL}$ of the $\mathrm{C}$ solution with $5 \mathrm{~mL}$ of the $\mathrm{P}$, resulting in a size-scale of $10 \mathrm{~mL}$ for the performed assays. Following, the final solution was vortexed, placed in a thermostatic bath during $5 \mathrm{~min}$ to achieve the required tested temperature $(T)$, and thereafter transferred to an ice bath during $20 \mathrm{~min}$. Final samples were then stored in a refrigerator $\left(4^{\circ} \mathrm{C}\right)$ during $24 \mathrm{~h}$, then centrifuged and the supernatant discharged. The formed coacervates were then washed in triplicate with the sodium acetate buffer solution $(5 \mathrm{~mL}$ each) to remove traces of free $\mathrm{P}$ and $\mathrm{C}$, and stored at $4{ }^{\circ} \mathrm{C}$, protected from light for further characterization.

\subsection{Characterization of the microencapsulation process}

\subsubsection{Quantification of the encapsulated ergosterol}

The encapsulated ergosterol was obtained by difference, i.e. based on the non-encapsulated ergosterol, quantified by HPLC according to the process described by Barreira et al. (2014), using a calibration curve based on a commercial standard. To recover the non-encapsulated ergosterol the obtained coacervates were washed with methanol in triplicate $(5 \mathrm{~mL}$ each). The combined methanol fractions were centrifuged at $6000 \mathrm{rpm}$ for $45 \mathrm{~min}$, filtered, dried under reduced pressure (rotary evaporator Büchi R-210, Flawil, Switzerland) and re-suspended in fresh methanol at a concentration of $10 \mathrm{mg} / \mathrm{mL}$. These samples were filtered with $0.2 \mu \mathrm{m}$ nylon syringe filters and analyzed by HPLC-UV.

\subsubsection{Microencapsulation yield, efficiency and load}

The microencapsulation process was characterized considering the microencapsulation yield, efficiency, and load. For the process yield determination, the obtained coacervates were lyophilized to determine the final weight achieved in the process. This weight was related with the theoretical weight (used amount of reactants: C, P and PE or EEE) and expressed in $\%(w / w)$. Microencapsulation efficiency, defined as the ratio between the weight of encapsulated ergosterol and the theoretical one (ergosterol used in the encapsulation process), was expressed in $\%(\mathrm{w} / \mathrm{w})$. Microencapsulation load, defined as the ratio between the weight of encapsulated ergosterol and the weight of achieved microcapsules was also expressed in $\%(w / w)$.

\subsubsection{Optical microscopy analysis}

The final morphology of the obtained microcapsules was analyzed by optical microscopy (Nikon Eclipse 50i microscope (Tokyo, Japan)), equipped with a Nikon Digital Sight camera and NIS Elements software for data acquisition at 40,100 and $400 \mathrm{X}$ magnifications.

\subsection{Response surface methodology}

\subsubsection{Definition of the microencapsulation process responses}

To evaluate the microencapsulation process by RSM analysis, of EEE and PE, three responses were selected: Yield $\left(Y_{1}, \% \mathrm{w} / \mathrm{w}\right)$; microencapsulation efficiency $\left(Y_{2}, \% \mathrm{w} / \mathrm{w}\right)$ and loading $\left(Y_{3}, \% \mathrm{w} / \mathrm{w}\right)$, as defined in section 2.4.2.

\subsubsection{Preliminary analysis of the microencapsulation process variables}

The influence of different independent variables, such as $T, p H, P / C$ and the ergosterol content $(E)$, on the microencapsulation process were investigated using one-factor-at-a-time to select the significant ones and to determine their preliminary range. The effect of each variable was tested by changing it in a defined range, chosen according to data available in literature, while keeping the others fixed (Elmer et al., 2011; Gaonkar et al., 2014; Nedovic et al., 2011; Sanchez et al., 2006). Values used in this preliminary screening were: $p H$ (4.5-7.0), $P / C$ (0.5-30), $T\left(25-95^{\circ} \mathrm{C}\right)$ and $E(0-25 \mathrm{mg}$ for PE and 0-600 $\mathrm{mg}$ for EEE, values expressed per $10 \mathrm{~mL}$, the scale of the experiments). Concerning $E$ values, the used amount of EEE was calculated in terms of the ergosterol content to reproduced the used range for PE.

\subsubsection{Experimental design}

The RSM is typically used for analyzing problems in which one or more responses of interest are influenced by two or more variables. Following Preliminary analysis of the microencapsulation process variables (see discussion in section 3.1), only $T$ and $P / C$ variables were selected for the conducted the RSM analysis; $p H$ was kept constant at 5.5 (due to its negligible effect within the tested ranges, as explained in section 3.1) and the effect of $E$ was considered only for the analysis at the optimum conditions achieved for $T$ and $P / C$ (more details in section 3.1). Thus, in this first step of the study, $E$ concentration in the final solution of $10 \mathrm{~mL}$ was $108 \mu \mathrm{g} / \mathrm{mL}$ (equivalent amount of ergosterol present in the extract) for $\mathrm{PE}$, and $3 \mathrm{mg} / \mathrm{mL}$ for EEE. For the two analysed cases, PE and EEE microencapsulation, $\mathrm{Y}_{2}$ (microencapsulation efficiency) and $\mathrm{Y}_{3}$ (loading) were defined in terms of ergosterol. The combined effects of $T$ and $P / C$ ratio were tested using a circumscribed central composite design (CCCD), with three replicates per condition. The structure of a $C C C D$ considers 5 levels for each factor. The mathematical expressions used to calculate the design distribution, code and decode of the tested variables can be found in the supplemental section (Table A1 of supplemental material).

\subsubsection{Mathematical model}

The following second-order polynomial equation corresponds to the general model for the analysis of the produced RSM responses:

$Y=b_{0}+\sum_{i=1}^{n} b_{i} X_{i}+\sum_{\substack{i=1 \\ j>i}}^{n-1} \sum_{j=2}^{n} b_{i j} X_{i} X_{j}+\sum_{i=1}^{n} b_{i i} X_{i}^{2}$

where $Y$ is the dependent variable $\left(Y_{1}, Y_{2}\right.$ and $\left.Y_{3}\right)$ to be modelled, $X_{i}$ and $X_{j}$ the independent variables, $b_{o}$ the constant coefficient, $b_{i}$ the coefficient of linear effect, $b_{i j}$ the coefficient of interaction effect, $b_{i i}$ the coefficients of quadratic effect, and $n$ the number of considered variables.

\subsubsection{Simplex procedure for optimize the variables to a maximum response}

To optimize the microencapsulation conditions, the produced parametric model responses were integrated into a simplex tool to solve non-linear problems (Heleno et al., 2016; Pinela et al., 2016), and determine the variable's values that simultaneously maximize the responses. Restrictions were applied to the variable coded values to avoid unnatural conditions (i.e., lower values than $0 \%$ or higher values than $100 \%)$.

\subsection{Dose-response study of the E analysis at the optimal global responses}

Once the effects of $T$ and $P / C$ were depicted and the variable's conditions optimized to maximize $Y_{1}, Y_{2}$ and $Y_{3}$ responses, the effect of changing $E$ was studied at the optimal values. For this analysis, the previous procedure for microencapsulation was maintained, as well as the responses to evaluate $Y_{1}, Y_{2}$ and $Y_{3}$.

\subsection{Numerical methods and statistical analysis}

All fitting procedures, coefficient estimates and statistical calculations were performed using a Microsoft Excel spreadsheet, and the graphical illustrations were obtained with the software DeltaGraph V6. Fitting and statistical analyses of the experimental results, according to the proposed equations, were carried out in three phases:

1) Coefficients measurement was achieved using the nonlinear leastsquare (quasi-Newton) method provided by the macro Solver in Microsoft Excel (Kemmer \& Keller, 2010; Murado \& Prieto, 2013), 
Table 1

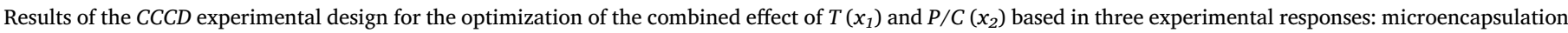

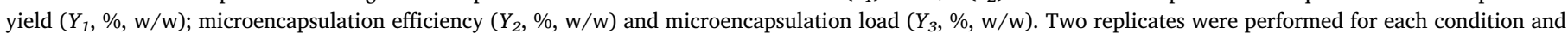
each response, and the average result is presented.

\begin{tabular}{|c|c|c|c|c|c|c|c|c|c|}
\hline \multirow{3}{*}{\multicolumn{2}{|c|}{$\begin{array}{l}\text { Variables } \\
\mathrm{X}_{1}: \mathrm{T}\end{array}$}} & & & \multicolumn{6}{|l|}{ Responses } \\
\hline & & & & \multicolumn{3}{|c|}{ Extracted material (EEE) } & \multicolumn{3}{|c|}{ Pure ergosterol (PE) } \\
\hline & & \multicolumn{2}{|c|}{$\mathrm{X}_{2}: \mathrm{P} / \mathrm{C}$ ratio } & $\mathrm{Y}_{1}$ : Yield & $\mathrm{Y}_{2}$ : Efficiency & $\mathrm{Y}_{3}$ : Load & $\mathrm{Y}_{1}$ : Yield & $\mathrm{Y}_{2}$ : Efficiency & $\mathrm{Y}_{3}$ : Load \\
\hline \multicolumn{2}{|l|}{$\left({ }^{\circ} \mathrm{C}\right)$} & \multicolumn{2}{|l|}{-} & $(\%, w / w)$ & $(\%, w / w)$ & $(\%, w / w)$ & $(\%, w / w)$ & $(\%, w / w)$ & $(\%, \mathrm{w} / \mathrm{w}$ \\
\hline-1 & (65) & -1 & (3) & 6.95 & 92.06 & 6.77 & 6.67 & 90.97 & 8.00 \\
\hline 1 & (85) & -1 & (3) & 22.89 & 88.97 & 1.98 & 38.83 & 24.29 & 0.36 \\
\hline-1 & (65) & 1 & (8) & 3.27 & 98.55 & 7.31 & 4.24 & 98.99 & 5.99 \\
\hline 1 & (85) & 1 & (8) & 32.09 & 94.50 & 0.71 & 48.82 & 1.07 & 0.01 \\
\hline-2 & (55) & 0 & $(5.5)$ & 4.46 & 93.51 & 6.88 & 5.36 & 99.18 & 6.57 \\
\hline 2 & (95) & 0 & $(5.5)$ & 61.04 & 95.66 & 0.51 & 72.51 & 16.78 & 0.08 \\
\hline 0 & (75) & -2 & $(0.5)$ & 11.55 & 94.10 & 9.00 & 13.15 & 94.30 & 10.93 \\
\hline 0 & (75) & 2 & (10.5) & 13.16 & 92.65 & 1.36 & 13.93 & 65.61 & 0.95 \\
\hline 0 & (75) & 0 & (5.5) & 8.33 & 89.56 & 3.51 & 8.03 & 83.53 & 3.71 \\
\hline 0 & (75) & 0 & (5.5) & 9.88 & 89.73 & 2.97 & 9.36 & 73.30 & 2.80 \\
\hline 0 & (75) & 0 & (5.5) & 9.93 & 85.99 & 2.82 & 10.13 & 99.43 & 3.50 \\
\hline
\end{tabular}

by minimization of the sum of quadratic differences between observed and model-predicted values.

2) Coefficients significance was obtained via 'SolverAid' (Prikler, 2009) to determine the parametric confidence intervals. The terms that were not statistically significant (p-value $>0.05$ ) were removed to simplify the model.

3) Model reliability was confirmed by applying the following standards: a) the Fisher $F$-test ( $\alpha=0.05$ ) to determine the consistency of the constructed models in describing the obtained data (Borges, Carvalho, Correia, \& Silva, 2007); b), the 'SolverStat' macro to make assessment of parameter and model prediction uncertainties (Shi \& Tsai, 2002); c) Correlation coefficient $\left(R^{2}\right)$ and adjusted coefficient of multiple determination $\left(R_{a d j}^{2}\right)$ to explain the proportion of variability of the dependent variable obtained by the model.

\section{Results and discussion}

\subsection{Selection of the relevant system variables and working ranges for the RSM optimization study}

A preliminary assessment was performed in one-variable-at-thetime procedure to investigate $T, p H, P / C$ and $E$. The obtained results were similar, either for ergosterol used in its PE form or as EEE. Changes in $E$ did not show any interaction with the other variables, and, therefore this variable was not selected for the RSM optimization study. However, since it is a relevant parameter from an industrial point of view, it was subsequently investigated by a dose-response approach.

The best response for yield was obtained at $p H 5.5$ using a $P / C$ of 3 and 5. As the $P$ content increases $(P / C$ of 10 and 25), the highest achieved yield was obtained at lower $p H s$ ( $p H 5.0$ ), but with values inferior to the ones registered at $p H 5.5$, for $P / C$ of 3 and 5 . In a general way, the magnitude of the maximum achieved yield is consistent with values reported by other authors (Lim, 2012). In CP, $p H$ assumes an important role, with the maximum coacervates formation occurring when the two polymers have opposite charge (Comuzzi, Polese, Melchior, Portanova, \& Tolazzi, 2003), which happens in a $p H$ range comprised between the $\mathrm{P}$ and $\mathrm{C}$ isoelectric points (4.7 and 6.4, respectively). In chitosan-protein systems, $\mathrm{C}$ provides the positive charged polymer, whereas the $\mathrm{P}$ the negative one. Since the favorable conditions were positioned within the two isoelectric points, which corresponds to a narrow practical $p H$ interval (with only minor improvements observed in this preliminary analysis), $p H$ was not selected, being excluded in the subsequent RSM study (a fix pH value of 5.5 was used).

The effect of $T$ pointed out for important differences within the tested range. It is well known that $\mathrm{P}$ denaturation causes its precipitation and the reaching of these conditions can favor the $\mathrm{CP}$, and thus increase the process yield. Theoretically, the increase in $T$ gives rise to $\mathrm{P}$ denaturation (i.e. unfolding), allowing a higher exposure of the protein's groups, thus promoting the combination with $\mathrm{C}$, and enhancing the formation of the coacervates (Neves, Matos, Moutinho, Queiroz, \& Gomes, 2009). Regarding ergosterol microencapsulation, no data was found in the literature, but, the performed preliminary tests suggested that the increase in $T$ favors ergosterol encapsulation efficiency. For this reason, $T$ was selected as a relevant variable for the RSM study.

In what concerns the $P / C$ effect, high differences were found within the tested range. As the $P / C$ increases, the number of negative charges provided by the protein hydrocolloid also increases. This fact can promote supplementary repulsions between the $\mathrm{P}$ molecules, but if the $P / C$ is at the optimal value the repulsion effects become lower, facilitating the interaction between the oppositely charged molecules, improving ergosterol entrapment (i.e. increasing microencapsulation efficiency). These effects where important from an optimization point of view and thus, $P / C$ variable was selected for the RSM study.

From this preliminary assessment, responses were optimized using a two-step procedure as follows: firstly, the application of a RSM was used to optimize the conditions of $T$ (from 55 to $95^{\circ} \mathrm{C}$ ) and $P / C$ (from 0.5 to 10.5), to maximize the $Y_{1}, Y_{2}$ and $Y_{3}$ responses with a $C C C D$; secondly, $E$ was optimized according to a dose-response study and considering the optimal conditions previously determined by the RSM analysis.

\subsection{RSM optimization and experimental verification of the model results prediction}

3.2.1. Development of the theoretical response surface models and statistical verification

Table 1 shows the average results (three replicates per assay were used) according to the statistical CCCD described in Table A1 for each of the defined responses $\left(Y_{1}, Y_{2}\right.$ and $\left.Y_{3}\right)$. Estimated parametric values, parametric intervals and numerical statistical criteria were obtained and are presented in Table A2. Coefficients presenting interval values ( $\alpha=0.05$ ) higher than the parameter value were considered as not significant (ns) and were not used for the model development. 
A: 3D JOIN ACTION
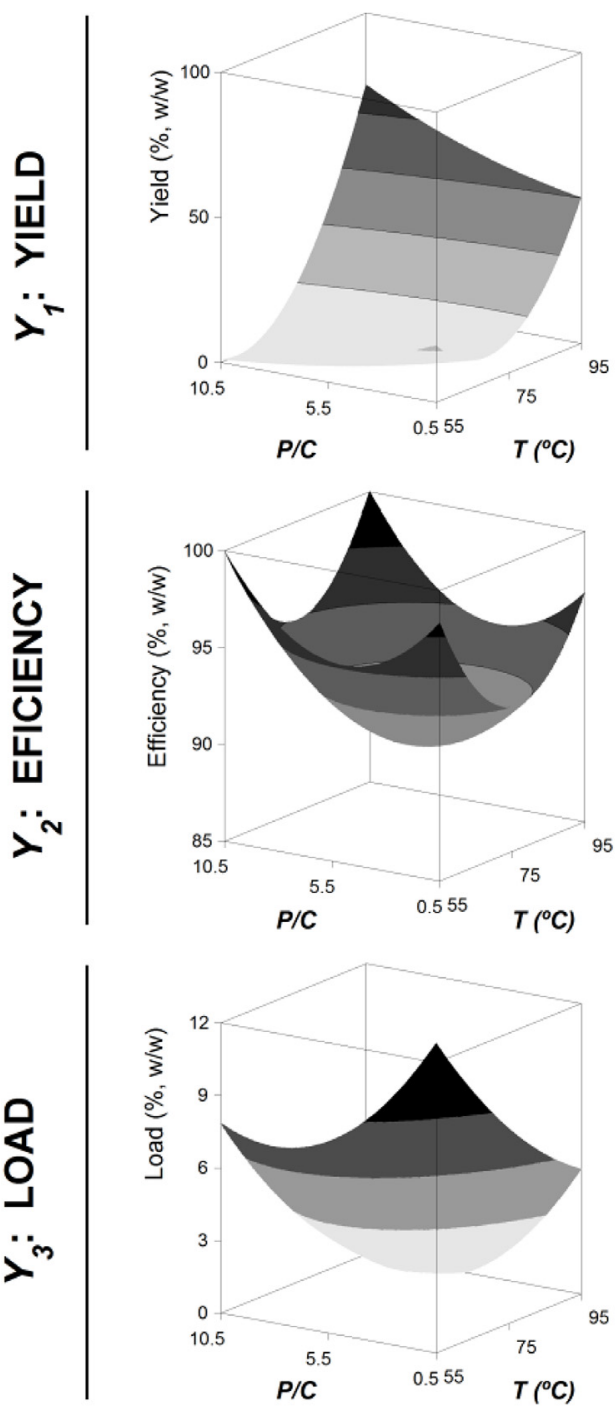

B: CONTOUR PLOT
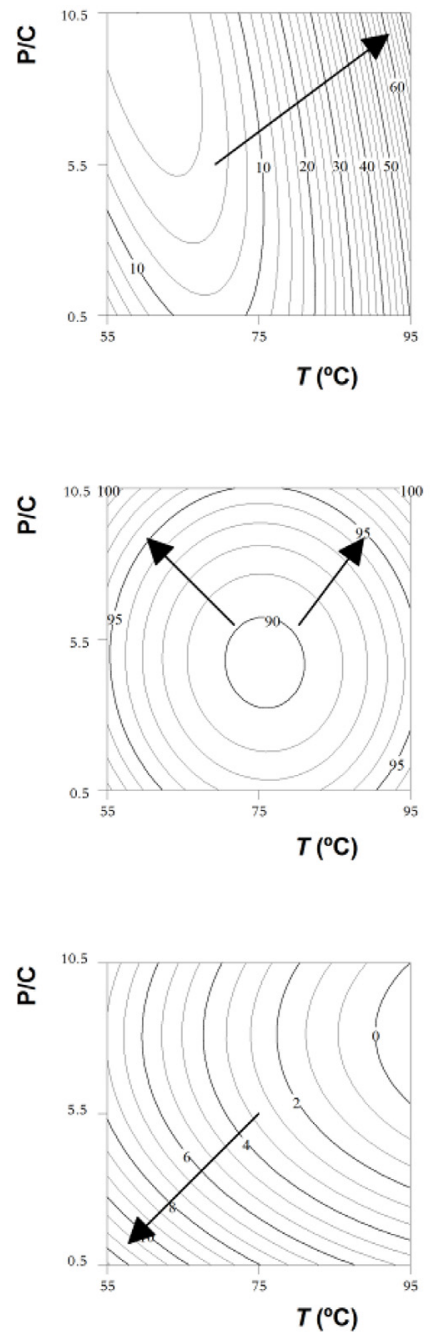

\section{C: STATISTICAL ANALYSIS}
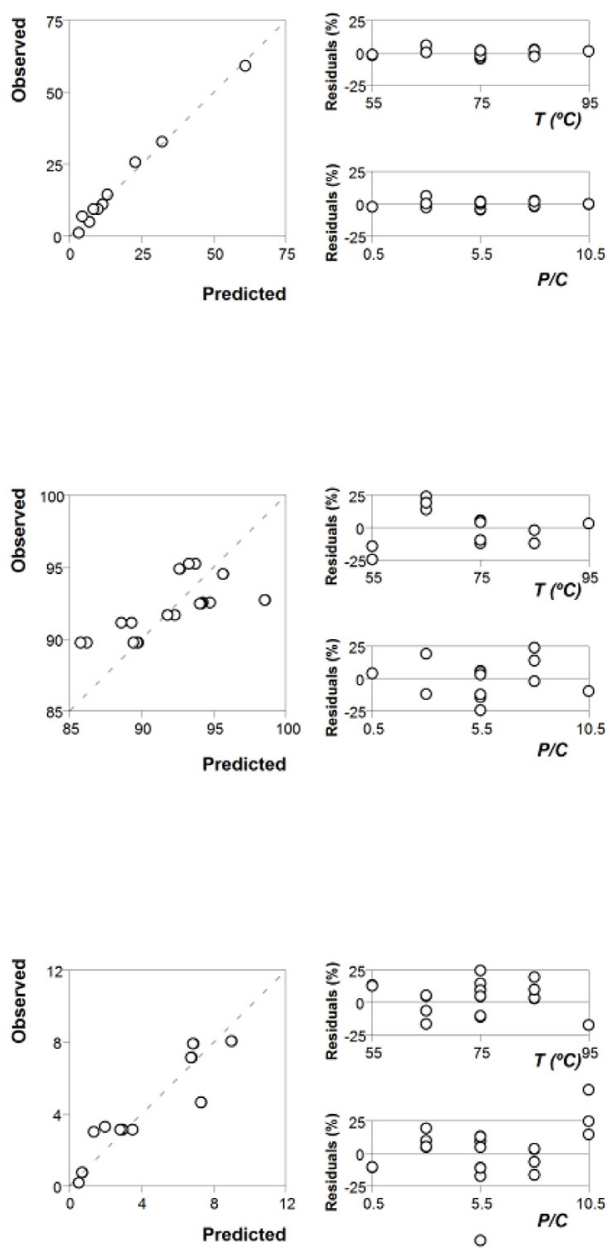

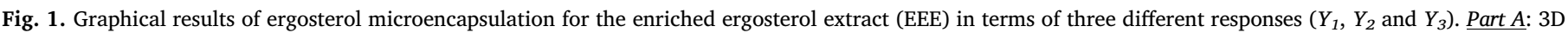

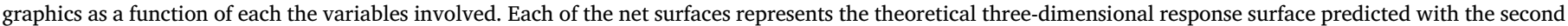

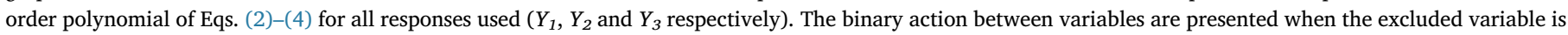

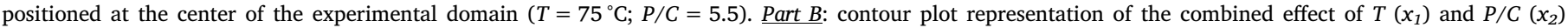
presenting the isolines of all response value formats. Part $C$ : predicted $v s$ observed data and residual plot distribution.

Models using coded values for each response were obtained by fitting the second-order polynomial model of Eq. [1] to the experimental values (Table 1) through nonlinear least-squares estimations. Parametric results are presented in Table A2 and the obtained models described in Eq. (2)-(4) for EEE, and in Eq. (5)-(7) for PE samples.

$Y_{1}^{E E E}=9.4+13.1 x_{1}+0.8 x_{2}+5.9 x_{1}^{2}+0.8 x_{2}^{2}+2.7 x_{1} x_{2}$

$Y_{2}^{E E E}=89.7+0.6 x_{2}+1.3 x_{1}^{2}+1.0 x_{2}^{2}$

$Y_{3}^{E E E}=3.1-1.9 x_{1}-1.3 x_{2}+0.23 x_{1}^{2}+0.6 x_{2}^{2}+0.01 x_{1} x_{2}$

$Y_{1}^{P E}=11.9+17.5 x_{12}+7.3 x_{1}^{2}+1.0 x_{2}^{2}$

$Y_{2}^{P E}=73.8-23.1 x_{1}-2.0 x_{2}-5.2 x_{1}^{2}+0.3 x_{2}^{2}-1.0 x_{1} x_{2}$

$Y_{3}^{P E}=3.1-1.9 x_{1}-1.9 x_{2}+0.2 x_{1}^{2}+0.7 x_{2}^{2}+0.4 x_{1} x_{2}$

where $T\left(x_{1}\right)$ and $P / C\left(x_{2}\right)$ are the variables and $Y_{1}, Y_{2}$ and $Y_{3}$ the responses. Only parameters showing statistically significant confidence intervals in Eq. [1] were used for model development. Equations (2)-(7) translate the response patterns for each studied case showing a highly complex behavior (Table A2). Linear and quadratic effects were found to play an important and significant role for all studied conditions. Regarding the interaction between variables, only in two cases it was not considered significant, and almost all interactive effects were in a positive mode.

Although the model coefficients are empirical values, and may not be related with physical or chemical significance, they are of great importance helping to predict the results for non-experimental conditions; its numerical value and sign mark the performance of the response (Gaonkar et al., 2014; Klemmer, Waldner, Stone, Low, \& Nickerson, 2012). Thus, when a factor has a positive sign a proportional relationship with the response is observed; on the other hand, when the effect is negative an inversely proportional relationship applies (Kurukji et al., 2014). Moreover, the higher is the absolute value of the coefficient, the more important is the weight of this variable in the response.

Several statistical tests were used to evaluate the obtained models 
A: 3D JOIN ACTION
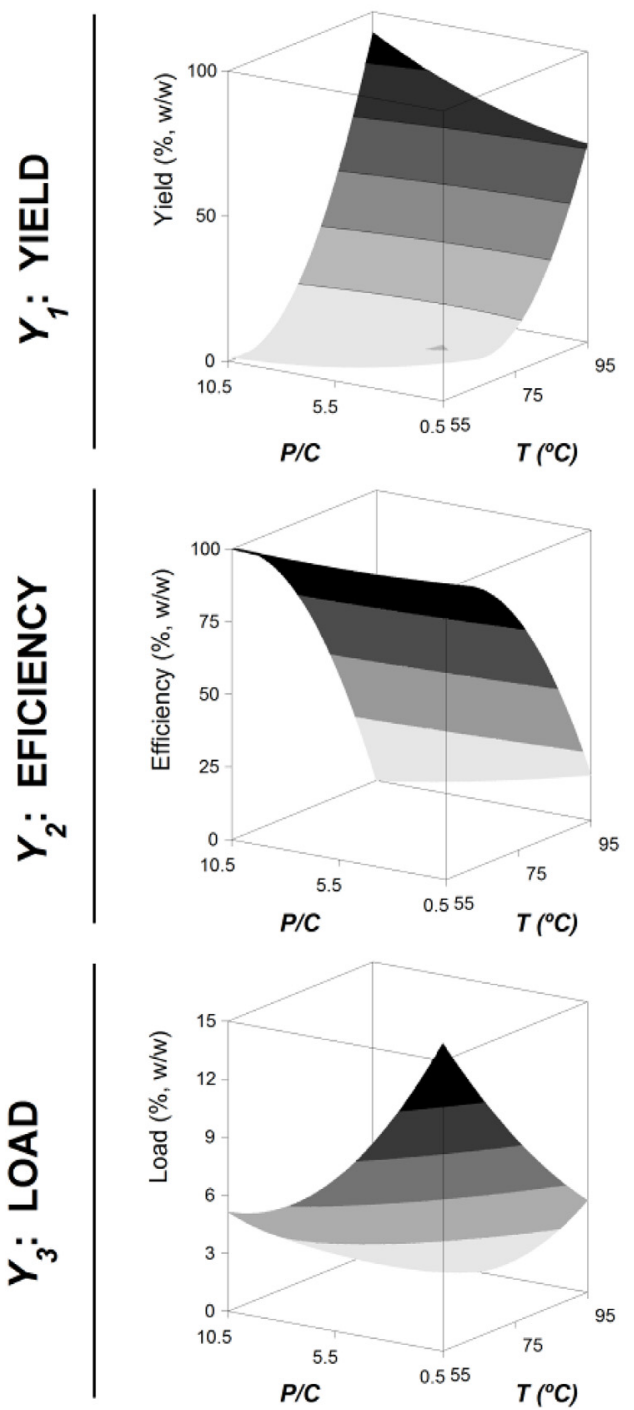

B: CONTOUR PLOT

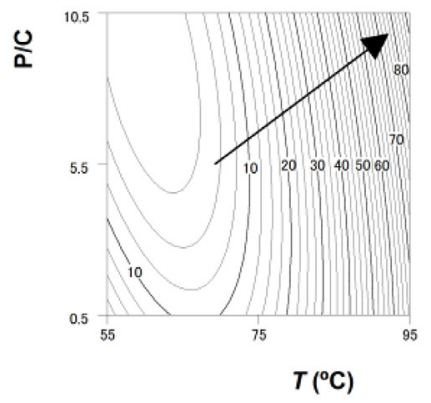

$\frac{O}{2}$
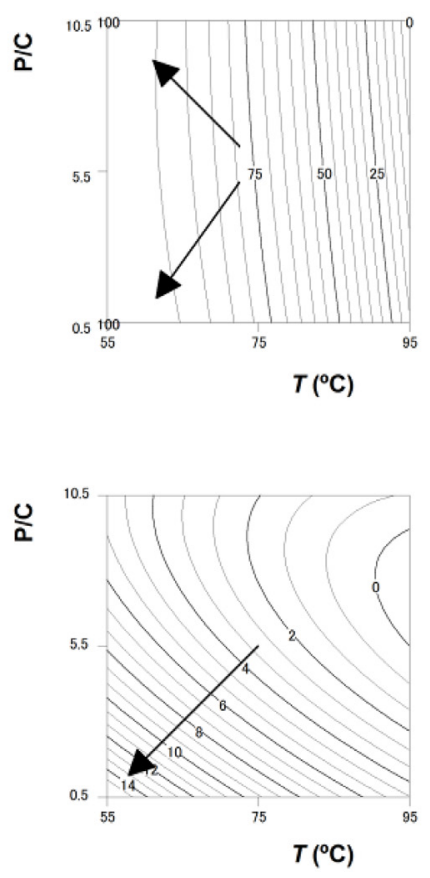
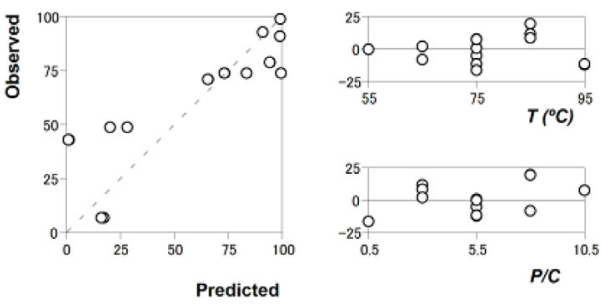

\section{C: STATISTICAL ANALYSIS}
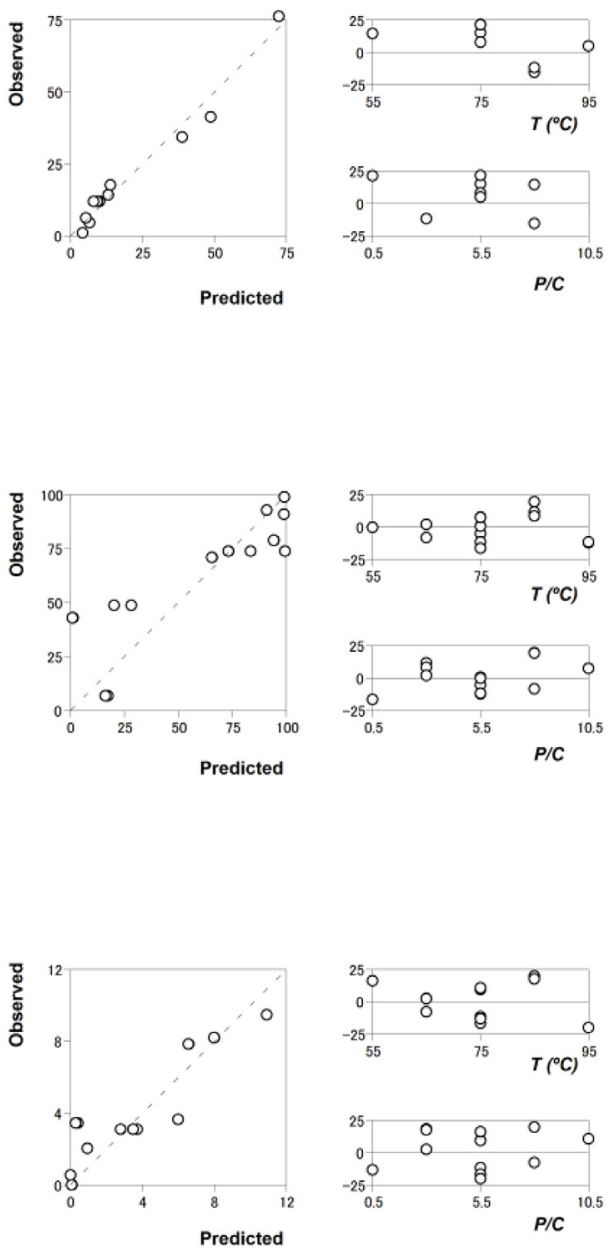

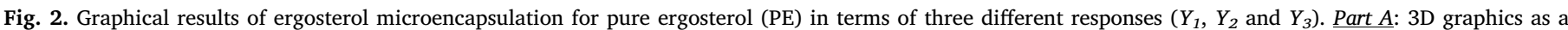

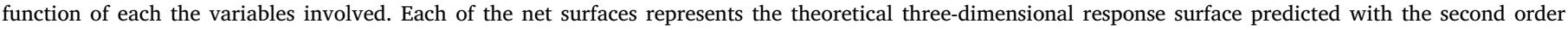

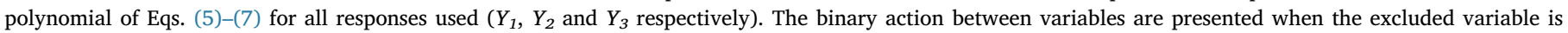

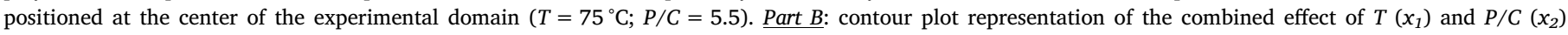
presenting the isolines of all response value formats. Part $C$ : predicted $v s$ observed data and residual plot distribution.

(Eqs. (2)-(7)), being observed that no considerable improvement was achieved by the exclusion of the non-statistically significant effects (Table A2). This was also corroborated by the achieved $\mathrm{R}^{2}$ and $\mathrm{R}_{\text {adj }}^{2}$ values (Table A2), which did not diminish by excluding these non-significant coefficients. Moreover, the obtained correlation coefficients for the three defined responses, for both studied cases (EEE and PE), showed high correlation between predicted and experimental data. As an example, $Y_{1}$ response (microencapsulation yield) for the EEE presented the highest $R^{2}$ value $(0.9898)$, whereas the lowest value was obtained in the PE case for $Y_{3}$ response (loading) with a $R^{2}$ of 0.8840 . Both values are high enough to indicate that the obtained experimental data is satisfactorily describe by the models.

\subsubsection{Effects of CP variables on the response criteria used to evaluate the} microencapsulation process

CP may be described by means of the parametric values of the second-order polynomial models defined in Eqs. (2)-(7). Alternatively, graphical representations facilitate the analysis of the complex relationships that might exist between the experimental variables. Fig. 1 and Fig. 2 shows the graphical results of ergosterol microencapsulation in terms of the three analyzed responses $\left(Y_{1}, Y_{2}\right.$ and $\left.Y_{3}\right)$, for EEE and PE, respectively. Part A shows the joint 3D-graphical analysis as a function of each involved variable $(T$ and $P / C)$. Each of the net surfaces represents the theoretical three-dimensional response surface predicted by the second order polynomial in Eq. [1] for $Y_{1}, Y_{2}$ and $Y_{3}$. Part B presents the contour plot representation of the combined effect of $T\left(x_{1}\right)$ and $P / C\left(x_{2}\right)$ presenting the isolines of all response value formats to guide the selection of the most favorable conditions. Part $\mathrm{C}$ presents the predicted $v s$ observed data graphic and the residual distribution (\%) as a function of each one of the variables.

The $Y_{1}$ (microencapsulation yield) varied from 3.27 to $61.04 \%$ and from 4.24 to $72.51 \%$ for EEE and PE cases, respectively. With both ergosterol sources, the lowest $Y_{1}$ value was obtained at $65^{\circ} \mathrm{C}$ and $P / C$ ratio of 8; the higher value was obtained at $95^{\circ} \mathrm{C}$ and $P / C$ of 5.5 .

For $Y_{2}$ (microencapsulation efficiency), the shown behavior pattern for the EEE and PE differed. In the case of EEE, the lowest $Y_{2}$ value 
Table 2

Optimal variable conditions of ergosterol microencapsulation for the enriched ergosterol extract (EEE) and pure ergosterol (PE) in terms of three different responses $\left(Y_{1}, Y_{2}\right.$ and $\left.Y_{3}\right)$. Intermediary variable conditions that optimize the response for all responses are computed.

\begin{tabular}{|c|c|c|c|}
\hline \multirow[t]{2}{*}{ Criteria } & \multicolumn{2}{|c|}{ Optimal variable conditions } & \multirow[t]{2}{*}{ Optimum response } \\
\hline & $\mathrm{X}_{1}: \mathrm{T}\left({ }^{\circ} \mathrm{C}\right)$ & $\mathrm{X}_{2}: \mathrm{P} / \mathrm{C}$ ratio & \\
\hline \multicolumn{4}{|c|}{ EXTRACTED MATERIAL (EEE) } \\
\hline \multicolumn{4}{|c|}{ Individual optimal variable conditions } \\
\hline$Y_{1}$ & $95.0 \pm 8.7^{b}$ & $10.48 \pm 0.97^{a}$ & $75.02 \%(w / w)$ \\
\hline$Y_{2}$ & $55.0 \pm 3.7^{b}$ & $10.5 \pm 0.85^{b}$ & $100.00 \%(w / w)$ \\
\hline$Y_{3}$ & $55.0 \pm 9.1$ & $0.5 \pm 0.02^{b}$ & $12.78 \%(w / w)$ \\
\hline \multicolumn{4}{|c|}{ Global optimal variable conditions } \\
\hline$Y_{1}$ & $55.0 \pm 6.9^{b}$ & $0.5 \pm 0.10^{b}$ & $19.46 \%(w / w)$ \\
\hline$Y_{2}$ & & & $98.32 \%(w / w)$ \\
\hline$Y_{3}$ & & & $12.78 \%(w / w)$ \\
\hline \multicolumn{4}{|c|}{ PURE ERGOSTEROL (PE) } \\
\hline \multicolumn{4}{|c|}{ Individual optimal variable conditions } \\
\hline$Y_{1}$ & $95.0 \pm 4.1^{b}$ & $10.5 \pm 0.31^{b}$ & $92.66 \%(w / w)$ \\
\hline$Y_{2}$ & $55.0 \pm 5.2^{b}$ & $0.5 \pm 0.32^{b}$ & $100.00 \%(w / w)$ \\
\hline$Y_{3}$ & $55.0 \pm 7.1$ & $0.5 \pm 0.24^{b}$ & $15.87 \%(w / w)$ \\
\hline \multicolumn{4}{|c|}{ Global optimal variable conditions } \\
\hline$Y_{1}$ & $55.0 \pm 8.4^{b}$ & $0.5 \pm 2.2^{b}$ & $19.19 \%(w / w)$ \\
\hline$Y_{2}$ & & & $100.00 \%(w / w)$ \\
\hline$Y_{3}$ & & & $15.87 \%(w / w)$ \\
\hline
\end{tabular}

a Conditions that lead to an absolute optimum response.

b Conditions that lead to a relative optimum response within the experimental design (from -2 to +2 ).

(85.99\%) was obtained at $75^{\circ} \mathrm{C}$ and $P / C$ ratio of 5.5. For PE, the lowest microencapsulation efficiency was $1.07 \%$ at $85^{\circ} \mathrm{C}$ and $P / C$ of 8.0 . Maximum efficiency values (98.55\%) occurred at $65^{\circ} \mathrm{C}$ and $P / C$ ratio of 8.0 for EEE case, whereas for PE $99.43 \%$ was reached at $75^{\circ} \mathrm{C}$ and $\mathrm{P} / \mathrm{C}$ of 5.5 .

For $Y_{3}$ response (microencapsulation load) the values ranged from 0.51 to $9.00 \%$ and $0.01-10.93 \%$ for EEE and PE, respectively. The maximum values, obtained for both ergosterol sources, occurred at $75{ }^{\circ} \mathrm{C}$ with $P / C$ of 0.5 . The lowest values occurred at $95^{\circ} \mathrm{C}$ with $P / C$ of 5.5 (EEE), and $85^{\circ} \mathrm{C}$ with $P / C$ of 8.0 (PE).

It is worth noting that in all cases the residuals distribution was always randomly scattered around zero with no found grouped data and autocorrelations (data not shown). This means that the proposed models are functional and may be applied to subsequent prediction and optimization stages. Also, it indicates a good agreement between the experimental and predicted values.

The maximum values for the $Y_{1}$ were found at high $T$ values, and the optimal values for $Y_{2}$ and $Y_{3}$ achieved at $T$ values below $75^{\circ} \mathrm{C}$. This fact may be related with the occurrence of protein denaturation; whey protein is mainly formed by $\beta$-lactoglobulin which is a thermosensitive globular protein presenting structural reversible changes at $50^{\circ} \mathrm{C}$, and irreversible ones at $70^{\circ} \mathrm{C}$. The increase of the hydrophobic groups exposition may promote a better association with ergosterol since it is also a hydrophobic molecule (Barros, Oliveira, Carvalho, \& Ferreira, 2010; de Vasconcelos, Bennett, Rosa, \& Ferreira-Cardoso, 2010). The high $Y_{2}$ observed for the lower $P / C$ tested may be related with the amount of presented charged groups.

\subsection{Optimization of the encapsulation conditions}

In mathematical terms, it is possible to obtain the individual and the global optimal conditions of the variables leading to the maximal response values $\left(Y_{1}, Y_{2}\right.$ and $\left.Y_{3}\right)$, by applying a simplex procedure considering restrictions to the experimental ranges. The obtained individual and global optimal conditions are shown in Table 2. In addition, Fig. 3 shows the individual optimal conditions for the defined variables $(P / C$ in the right side, and $T$ in the left side of the figure) with $\mathrm{PE}$ and EEE cases assigned by light and dark curves, respectively. The

\section{$Y_{1}:$ YIELD}
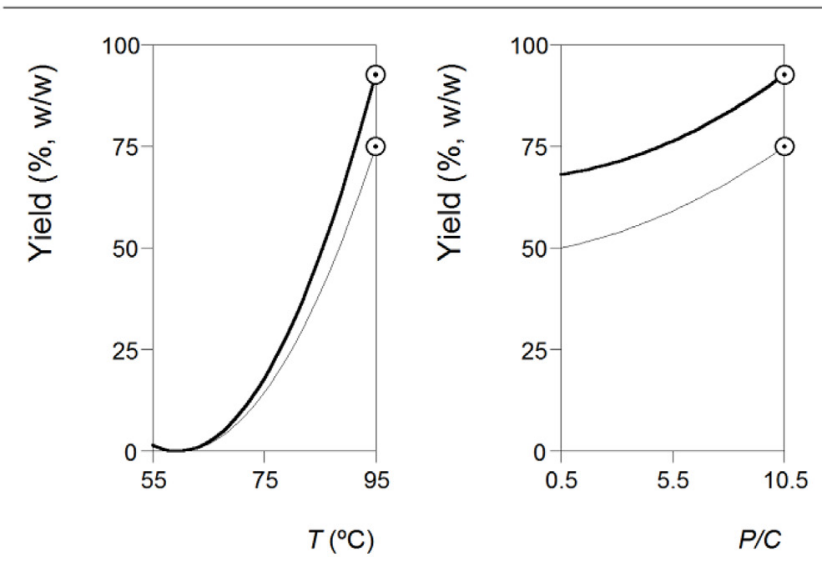

\section{$Y_{2}:$ EFFICIENCY}
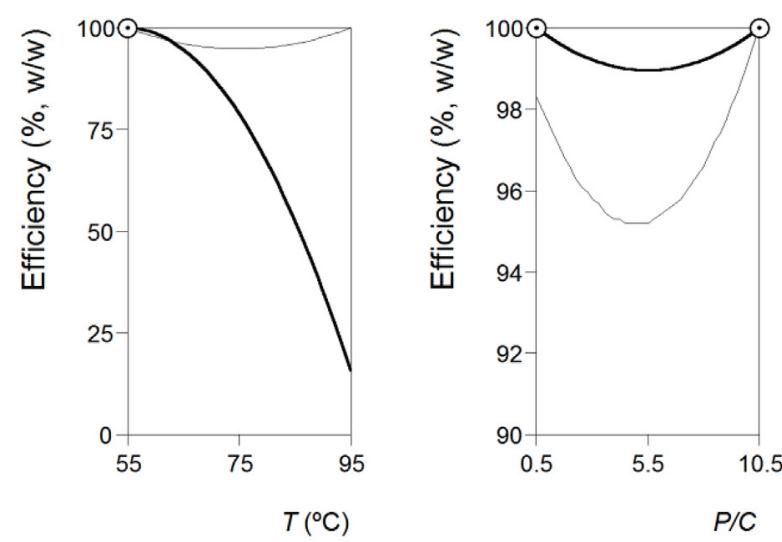

\section{$Y_{3}:$ LOAD}
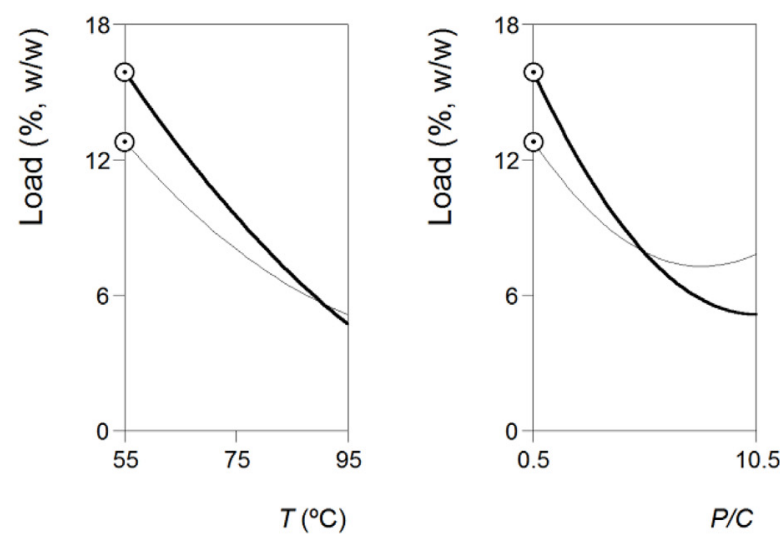

Fig. 3. Individual 2D graphics of $Y_{1}, Y_{2}$ and $Y_{3}$ for each variable (thinner line: pure ergosterol, thicker line enriched ergosterol extract). All other variables are located at the optimal conditions found. Dots $(\odot)$ presented alongside each line highlights the location of the optimum value.

most noted difference between PE and EEE occurred for the variable $Y_{2}$; for PE it remained constant as $T$ increased, whereas for EEE $T$ increasing implied a reduction on the microencapsulation efficiency. For $P / C$ an opposite trend was observed, i.e. for EEE it remained nearly the constant (slightly concave). As the $P / C$ increase a prominent concavity around $P / C$ of 5.5 was observed when PE was used. Additionally, the 


\section{A: EXTRACT}

\section{$\mathrm{T}=55^{\circ} \mathrm{C} ; \mathrm{P} / \mathrm{C}=0.5$}
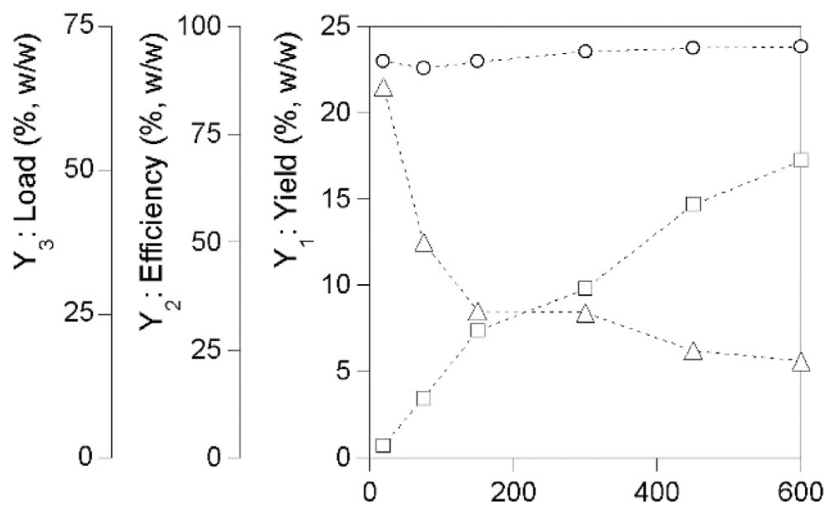

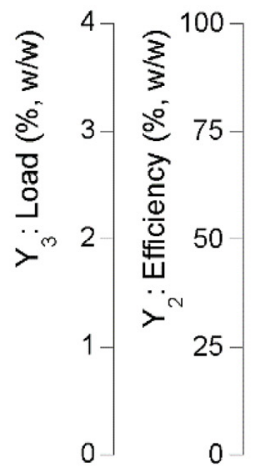

$\mathrm{T}=95^{\circ} \mathrm{C} ; \mathrm{P} / \mathrm{C}=10.5$

Extract $(\mathrm{mg})$

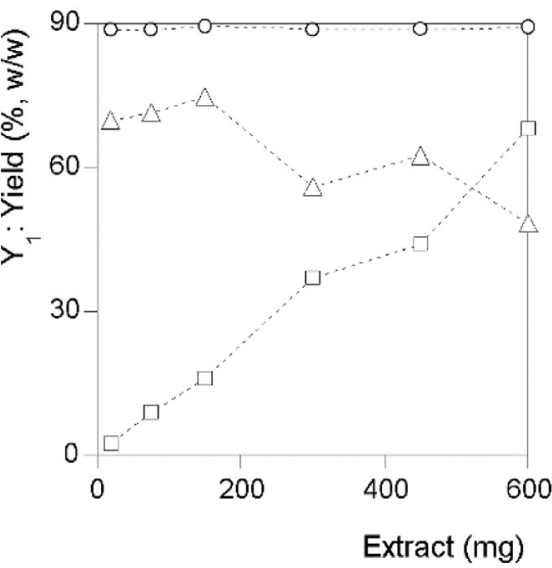

\section{B: ERGOSTEROL}

\section{$\mathrm{T}=55^{\circ} \mathrm{C} ; \mathrm{P} / \mathrm{C}=0.5$}
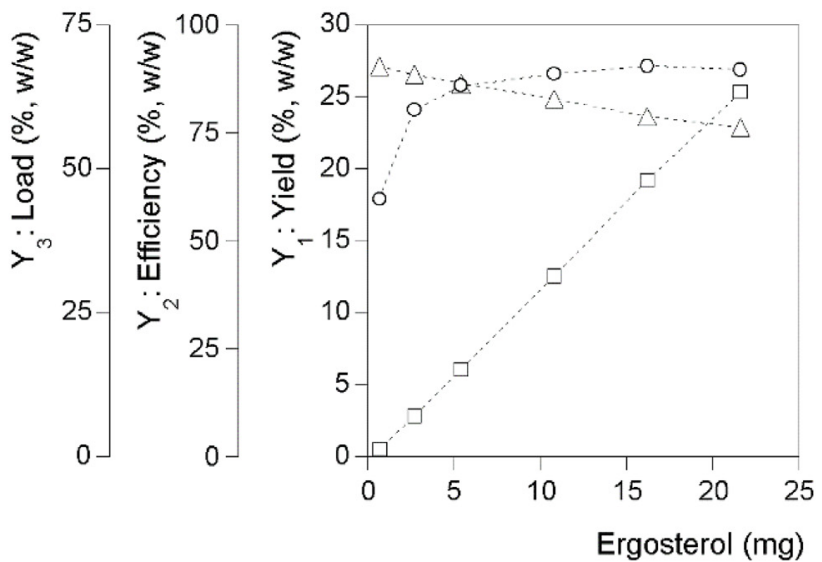

$\mathrm{T}=95^{\circ} \mathrm{C} ; \mathrm{P} / \mathrm{C}=10.5$
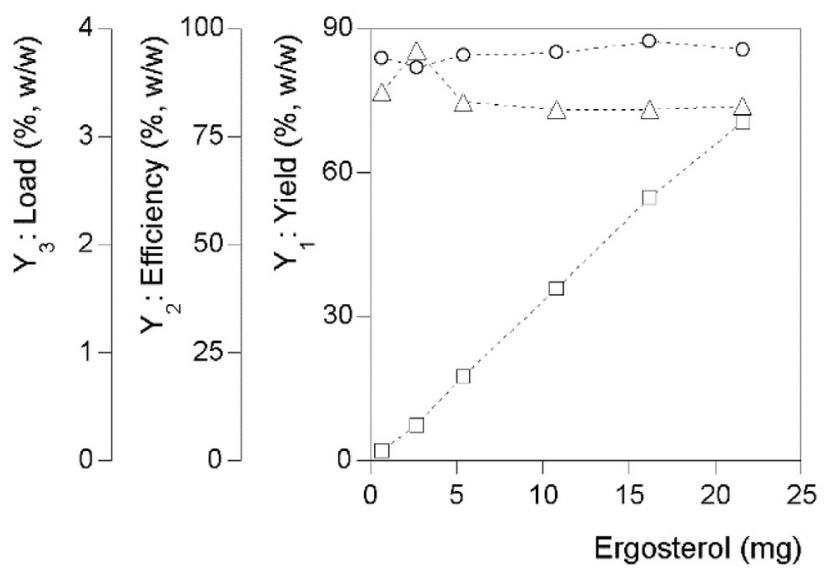

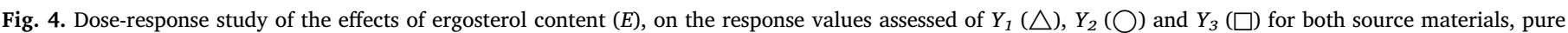
ergosterol (PE) and enriched ergosterol extract (EEE). Numerical results are presented in Table A3.

optimum conditions for EEE always lead to higher values than those obtained for PE. This may occur due to the presence of other molecules in the extract besides ergosterol, which affects the microencapsulation process. It may be hypothesized that those other molecules present in the EEE may create a "preferable path" favoring, in global terms, the entrapment of the surrounding molecules.

\subsection{Dose-response analysis of ergosterol encapsulation using EEE and PE at the optimal achieved microencapsulation conditions}

Two different optimal conditions for the $\mathrm{CP}$ were taken into account to evaluate the dose-response effect of $\mathrm{E}$ using the two ergosterol sources (EEE and PE) with responses shown in Table 2, Figs. 1, Figs. 2 and 3. condition $55^{\circ} \mathrm{C}$ and $P / C$ of 0.5 was chosen because it corresponds to an overall optimum value of almost all responses. condition $95^{\circ} \mathrm{C}$ and $P / C$ of 10.5 was also chosen since it leads to a high $Y_{1}$, which may be important from a productive point of view.

Table A3 and Fig. 4 show the obtained dose-responses (in terms of $Y_{1}, Y_{2}$ and $Y_{3}$ ) when EEE and PE ergosterol sources were used at the two considered optimal conditions.
The $Y_{1}$ remained constant as the ergosterol content decreased. At $55^{\circ} \mathrm{C}$ the increase in the $E$, for both ergosterol sources (PE and EEE), interfered in the final achieved yield. In fact, CP depends on the interaction between $\mathrm{P}$ and $\mathrm{C}$ molecules. It seems that the insertion of high ergosterol content promote the individual interaction of this molecule with the used coacervation materials, thus reducing coacervation yield. On the other hand, at $95^{\circ} \mathrm{C}$ higher yields were attained, comparatively with those obtained at $55^{\circ} \mathrm{C}$. As the $T$ increases, $\mathrm{P}$ denaturation also increases, thus the recovered coacervates may include some denatured $P$ itself.

For $Y_{2}$, at $55^{\circ} \mathrm{C}$ it was possible to detect a proportional relationship with $E$, both for the EEE and PE ergosterol sources. With PE, an optimum was achieved resulting from a possible saturation of the encapsulating material (achievement of a maximum load capacity), which was corroborated by the amount of ergosterol found outside the microcapsules.

For $Y_{3}$, in the two cases, a linear relationship with $E$ was found, with slightly higher values found at $55^{\circ} \mathrm{C}$, comparatively with $95^{\circ} \mathrm{C}$. For high $E$ values, the formed microcapsules may not be able to incorporate all the available ergosterol and therefore, asymptotic patterns were 


\section{PE}

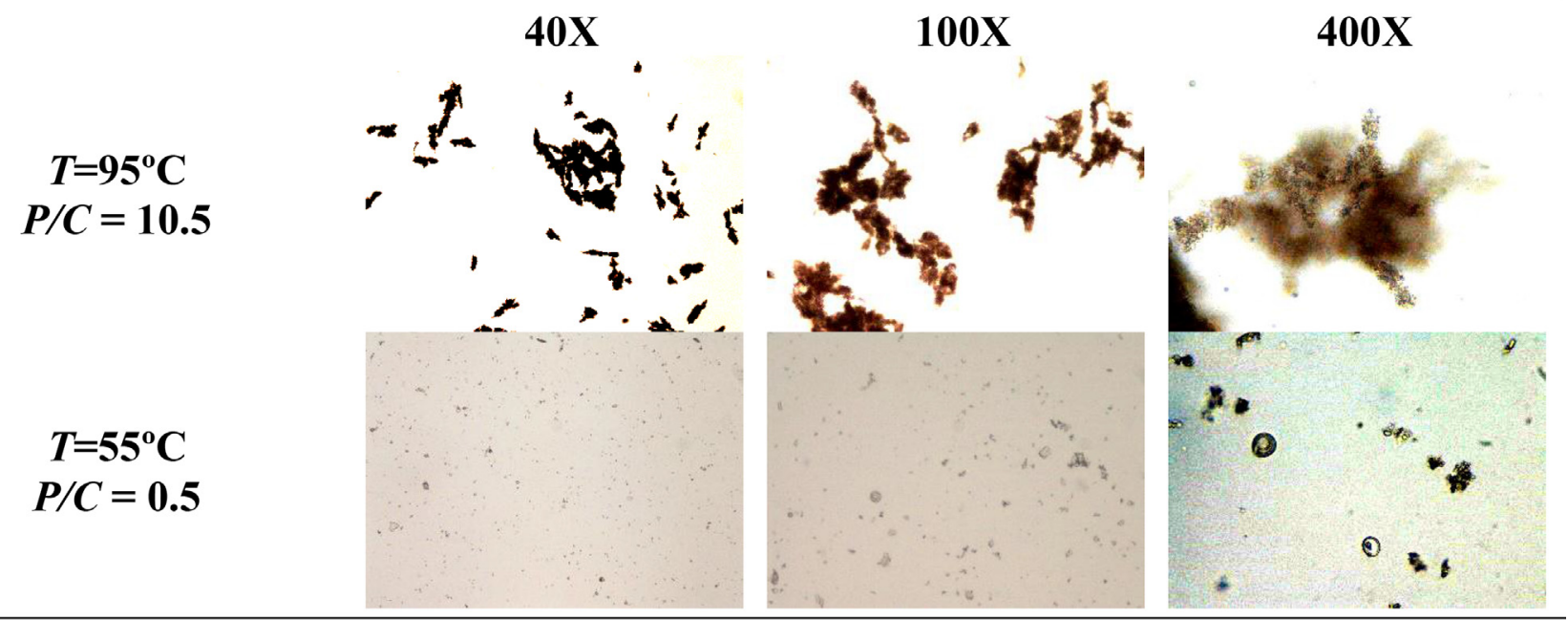

\section{EEE}

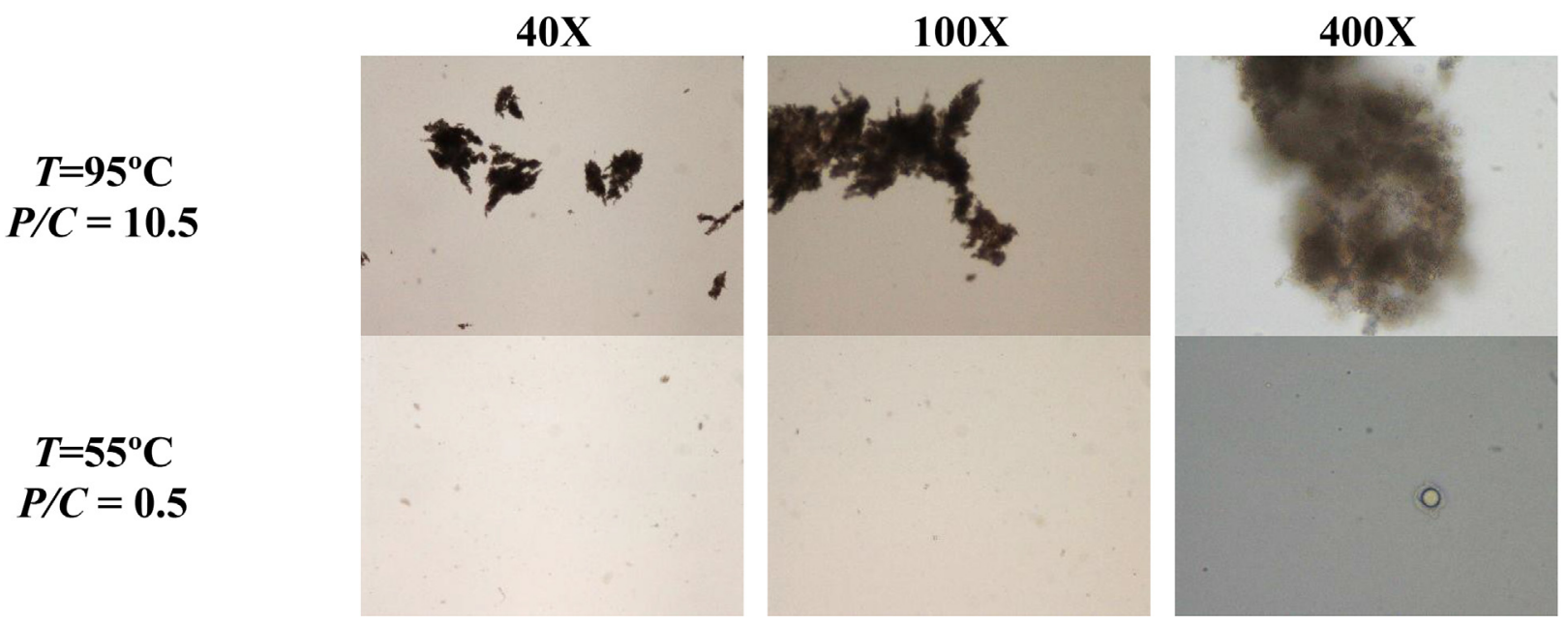

Fig. 5. Optical microscopy analysis of PE- and EEE-loaded microcapsules produced under the optimal conditions.

found.

According to Figure $\mathrm{A} 1$ and comparing PE and EEE samples, there are not significant differences at $95^{\circ} \mathrm{C}$ and $\mathrm{P} / \mathrm{C}$ ratio of 10.5 . This can be also corroborated in Fig. 4, where it is also verified that there is not much difference between the answers for these two optimal conditions. On the other hand, at $55^{\circ} \mathrm{C}$ and $\mathrm{P} / \mathrm{C}$ ratio of 0.5 differences between PE and EEE samples are observed, also well evident in Fig. 4). In Fig. 5 and A1, it can be also observed the effect of increasing the concentration of ergosterol in PE and in EEE samples.

Regarding the morphology at $95^{\circ} \mathrm{C}$, it can be perceived complex irregular clusters containing both extract and ergosterol inside. When a temperature of $55^{\circ} \mathrm{C}$ was used, the formed microcapsules are more defined presenting a round shape. In Fig. 4 it can be observed that under these established optimal conditions, higher ergosterol loads were obtained at this temperature.

\section{Conclusions}

Encapsulation of ergosterol using chitosan/whey protein coacervates is a viable alternative for the food industry. Both biopolymers are obtained from industrial wastes, highlighting the green connotations of the present work, and contributing for their valorization. The used mathematical models were statistically validated leading to the optimization of microencapsulation process (yield, efficiency and load). Moreover, the global optimal conditions for the encapsulation of ergosterol occurred at $55^{\circ} \mathrm{C}$ for a $P / C$ of 0.5 . It is further noted that the ergosterol presented in the enriched ergosterol extracts seems to be encapsulated more efficiently than the pure ergosterol itself, which may be associated with the presence of other molecules in the extract that may favor ergosterol entrapment. Finally, the effect of increasing $E$ (ergosterol content) in the processing responses, led to significant changes in the $Y_{1}$ (microencapsulation yield reduction) and $Y_{3}$ (microencapsulation load increase), while maintaining approximately constant the efficiency of the microencapsulation process $\left(Y_{2}\right)$.

\section{Acknowledgements}

The authors are grateful to the Foundation for Science and Technology (FCT, Portugal) and FEDER under Programme PT2020 for financial support to CIMO (UID/AGR/00690/2013), to European Structural and Investment Funds (FEEI) through the Regional Operational Program North 2020, within the scope of Project Mobilizador Norte-01-0247-FEDER-024479: ValorNatural ${ }^{\circledR}$, Sandrina A. Heleno (SFRH/BPD/101413/2014), L. Barros (SFRH/BPD/107855/ 2015) and Xunta de Galicia for financial support for the post-doctoral researcher of M.A. Prieto; POCI-01-0145-FEDER-006984 (LA LSRE- 
LCM), funded by FEDER, through POCI-COMPETE2020 and FCT; Project NORTE-01-0145-FEDER-000006.

\section{Appendix A. Supplementary data}

Supplementary data to this article can be found online at https:// doi.org/10.1016/j.lwt.2019.01.018.

\section{References}

Ach, D., Briançon, S., Dugas, V., Pelletier, J., Broze, G., \& Chevalier, Y. (2015). Influence of main whey protein components on the mechanism of complex coacervation with Acacia gum. Colloids and Surfaces A: Physicochemical and Engineering Aspects, 481, 367-374.

Ahmed, K. F., Aschi, A., \& Nicolai, T. (2018). Formation and characterization of chitosanprotein particles with fractal whey protein aggregates. Colloids and Surfaces B: Biointerfaces, 169(May), 257-264. https://doi.org/10.1016/j.colsurfb.2018.05.030.

Anema, S. G., \& Kruif, C. G. K. De (2016). Food Hydrocolloids Phase separation and composition of coacervates of lactoferrin and caseins. Food Hydrocolloids, 52, 670-677. https://doi.org/10.1016/j.foodhyd.2015.08.011.

Barreira, J. C. M., \& Ferreira, I. C. F. R. (2015). Steroids in natural matrices: Chemical features and bioactive properties. biotechnology of bioactive compounds: Sources and applications (First Edit).

Barreira, J. C. M., Oliveira, M. B. P. P., \& Ferreira, I. C. F. R. (2014). Development of a novel methodology for the analysis of ergosterol in mushrooms. Food Analytical Methods, 7, 217-223.

Barros, L., Oliveira, S., Carvalho, A. M., \& Ferreira, I. C. F. R. (2010). In vitro antioxidant properties and characterization in nutrients and phytochemicals of six medicinal plants from the Portuguese folk medicine. Industrial Crops and Products, 32(3), 572-579.

Bastos, D. S., Barreto, B. N., Souza, H. K. S., Bastos, M., Rocha-Leão, M. H. M., Andrade, C. T., et al. (2010). Characterization of a chitosan sample extracted from Brazilian shrimps and its application to obtain insoluble complexes with a commercial whey protein isolate. Food Hydrocolloids, 24(8), 709-718. https://doi.org/10.1016/j. foodhyd.2010.03.008.

Bastos, D. D. S., Gonçalves, M. D. P., Andrade, C. T. De, Araújo, K. G. D. L., \& Rocha Leão, M. H. M. Da. (2012). Microencapsulation of cashew apple (Anacardium occidentale, L.) juice using a new chitosan-commercial bovine whey protein isolate system in spray drying. Food and Bioproducts Processing, 90(4), 683-692.

Borges, O. P., Carvalho, J. S., Correia, P. R., \& Silva, A. P. (2007). Lipid and fatty acid profiles of Castanea sativa Mill. Chestnuts of 17 native Portuguese cultivars. Journal of Food Composition and Analysis, 20(2), 80-89.

Comuzzi, C., Polese, P., Melchior, A., Portanova, R., \& Tolazzi, M. (2003). SOLVERSTAT: A new utility for multipurpose analysis. An application to the investigation of dioxygenated Co (II) complex formation in dimethylsulfoxide solution. Talanta, 59(1), $67-80$.

Corrêa, R. C. G., Brugnari, T., Bracht, A., Peralta, R. M., \& Ferreira, I. C. F. R. (2016). Biotechnological, nutritional and therapeutic uses of pleurotus spp. (oyster mushroom) related with its chemical composition: A review on the past decade findings. Trends in Food Science \& Technology, 50, 103-117.

Corrêa, R. C. G., Peralta, R. M., Bracht, A., \& Ferreira, I. C. F. R. (2017). The emerging use of mycosterols in food industry along with the current trend of extended use of bioactive phytosterols. Trends in Food Science \& Technology, 67, 19-35.

Corredig, M. (2009). Dairy-derived ingredients Food and nutraceutical uses. New York - USA: CRC Press.

A detailed analysis of the recombination landscape of the button mushroom Agaricus bisporus var. bisporus. (n.d.).

Dias, M. I., Ferreira, I. C. F. R., \& Barreiro, M. F. (2015). Microencapsulation of bioactives for food applications. Food Function, 6(4), 1035-1052.

Edris, A. E., Kalemba, D., Adamiec, J., \& Piaotkowski, M. (2016). Microencapsulation of Nigella sativa oleoresin by spray drying for food and nutraceutical applications. Food Chemistry, 204, 326-333. https://doi.org/10.1016/j.foodchem.2016.02.143.

Elmer, C., Karaca, A. C., Low, N. H., \& Nickerson, M. T. (2011). Complex coacervation in pea protein isolate - chitosan mixtures. FRIN, 44(5), 1441-1446. https://doi.org/10. 1016/j.foodres.2011.03.011.

Ferreira, S. L. C., Bruns, R. E., Ferreira, H. S., Matos, G. D., David, J. M., Brandão, G. C., .. dos Santos, W. N. L. (2007). Box-Behnken design: An alternative for the optimization of analytical methods. Analytica Chimica Acta, 597(2), 179-186.

Francisco, C. R. L., Heleno, S. A., Fernandes, I. P. M., Barreira, J. C. M., Calhelha, R. C., Barros, L., ... Barreiro, M. F. (2018). Functionalization of yogurts with Agaricus bisporus extracts encapsulated in spray-dried maltodextrin crosslinked with citric acid. Food Chemistry, 245, 845-853 (November 2017).

Gaonkar, A., Vasisht, N., Khare, A., \& Sobel, R. (2014). Microencapsulation in the food industry a practical implementation guide. San Diego USA: Elsevier).

Getachew, A. T., \& Chun, B. S. (2016). Optimization of coffee oil flavor encapsulation using response surface methodology. Lebensmittel-Wissenschaft und-Technologie- Food Science and Technology, 70, 126-134.

Gil-ramírez, A., Ruiz-rodríguez, A., Marín, F. R., Reglero, G., \& Soler-rivas, C. (2014). Effect of ergosterol-enriched extracts obtained from Agaricus bisporus on cholesterol absorption using an in vitro digestion model. Journal of Functional Foods, 11 589-597.

Gulão, S., Souza, C. J. F. De, Fernanda, A. S., Coimbra, J. S. R., \& Garcia-rojas, E. E (2014). Complex coacervates obtained from lactoferrin and gum Arabic: Formation and characterization. FRIN, 65, 367-374. https://doi.org/10.1016/j.foodres.2014. 08.024.

Heleno, S. A., Diz, P., Prieto, M. A., Barros, L., Rodrigues, A., Barreiro, M. F., et al. (2016). Optimization of ultrasound-assisted extraction to obtain mycosterols from Agaricus bisporus L. by response surface methodology and comparison with conventional Soxhlet extraction. Food Chemistry, 197, 1054-1063.

Heleno, S. A., Rudke, A. R., Calhelha, R. C., Carocho, M., Barros, L., Gonçalves, O.C, .. Ferreira, I. C. F. R. (2017). Function development of dairy beverages functionalized with pure ergosterol and mycosterol extracts : An, -

Ifeduba, E. A., \& Akoh, C. C. (2016). Microencapsulation of stearidonic acid soybean oil in Maillard reaction-modified complex coacervates. Food Chemistry, 199, 524-532.

Kemmer, G., \& Keller, S. (2010). Nonlinear least-squares data fitting in Excel spreadsheets. Natural Protocols, 5(2), 267-281.

Klemmer, K. J., Waldner, L., Stone, A., Low, N. H., \& Nickerson, M. T. (2012). Complex coacervation of pea protein isolate and alginate polysaccharides. Food Chemistry, 130(3), 710-715.

Kurukji, D., Norton, I., \& Spyropoulos, F. (2014). Fabrication of sub-micron proteinchitosan electrostatic complexes for encapsulation and $\mathrm{pH}$-Modulated delivery of model hydrophilic active compounds. Food Hydrocolloids, 53, 249-260.

Kwak, H.-S. (2014). Nano and microencapsulation for foods. Chennai - India: Wiley Blackwell.

Lian, Z., Pan, R., \& Wang, J. (2016). Microencapsulation of norfloxacin in chitosan/ chitosan oligosaccharides and its application in shrimp culture. International Journal of Biological Macromolecules, 92, 587-592.

Lim, T. K. (2012). Edible medicinal and non-medicinal plants: Volume 2, fruits. Edible medicinal and non-medicinal plants. Fruits, Volume 2.

Liu, J., Jia, L., Kan, J., \& Jin, C. (2013). In vitro and in vivo antioxidant activity of ethanolic extract of white button mushroom (Agaricus bisporus). Food and Chemical Toxicology, 51, 310-316.

Murado, M. A., \& Prieto, M. A. (2013). Dose-response analysis in the joint action of two effectors. A new approach to simulation, identification and modelling of some basic interactions. PLoS One, 8(4), e61391.

Nedovic, V., Kalusevic, A., Manojlovic, V., Levic, S., \& Bugarski, B. (2011). An overview of encapsulation technologies for food applications. Procedia Food Science, 1, 1806-1815.

Neves, J. M., Matos, C., Moutinho, C., Queiroz, G., \& Gomes, L. R. (2009). Ethnopharmacological notes about ancient uses of medicinal plants in Trás-os-Montes (northern of Portugal). Journal of Ethnopharmacology, 124(2), 270-283.

Nisisako, T. (2016). Recent advances in microfluidic production of Janus droplets and particles. Current Opinion in Colloid \& Interface Science, 25, 1-12.

Pinela, J., Prieto, M. A., Barreiro, M. F., Carvalho, A. M., Oliveira, M. B. P. P., Vázquez, J. A., et al. (2016a). Optimization of microwave-assisted extraction of hydrophilic and lipophilic antioxidants from a surplus tomato crop by response surface methodology. Food and Bioproducts Processing, 98, 283-298.

Pinela, J., Prieto, M. A. A., Carvalho, A. M., Barreiro, M. F., Oliveira, M. B. P., Barros, L., et al. (2016b). Microwave-assisted extraction of phenolic acids and flavonoids and production of antioxidant ingredients from tomato: A nutraceutical-oriented optimization study. Separation and Purification Technology, 164, 114-124.

Prikler, S. (2009). Robert de Levie: Advanced Excel for scientific data analysis. 2nd ed Analytical and Bioanalytical Chemistry, 395(7), 1945.

Rasekh, M., Ahmad, Z., Cross, R., Hernández-Gil, J., Wilton-Ely, J. D. E. T., \& Miller, P. W. (2017). Facile preparation of drug-loaded tristearin encapsulated superparamagnetic iron oxide nanoparticles using coaxial electrospray processing. Molecular Pharmaceutics, 14(6), 2010-2023.

Sánchez, F. M., García, F., Calvo, P., Bernalte, M. J., \& González-gómez, D. (2016). Optimization of broccoli microencapsulation process by complex coacervation using response surface methodology. Innovative Food Science \& Emerging Technologies, 34, 243-249. https://doi.org/10.1016/j.ifset.2016.02.008.

Sanchez, C., Mekhloufi, G., \& Renard, D. (2006). Complex coacervation between $\beta$-lactoglobulin and Acacia gum: A nucleation and growth mechanism, vol. 299, 867-873. https://doi.org/10.1016/j.jcis.2006.02.031.

Sayed, E., Karavasili, C., Ruparelia, K., Haj-Ahmad, R., Charalambopoulou, G., Steriotis, T., ... Ahmad, Z. (2018). Electrosprayed mesoporous particles for improved aqueous solubility of a poorly water soluble anticancer agent: In vitro and ex vivo evaluation. Journal of Controlled Release, 278, 142-155 (November 2017).

Shi, P., \& Tsai, C.-L. (2002). Regression model selection: A residual likelihood approach. Journal of the Royal Statistical Society: Series B, 64(2), 237-252.

Sutaphanit, P., \& Chitprasert, P. (2014). Optimisation of microencapsulation of holy basil essential oil in gelatin by response surface methodology. Food Chemistry, 150, 313-320. https://doi.org/10.1016/j. foodchem.2013.10.159.

Tavares, L., \& Noreña, C. P. Z. (2019). Encapsulation of garlic extract using complex coacervation with whey protein isolate and chitosan as wall materials followed by spray drying. Food Hydrocolloids, 89, 360-369 (July 2018).

Tolve, R., Condelli, N., Caruso, M. C., Genovese, F., Renzo, C. G. Di, Mauriello, G., et al (2018). Preparation and characterization of microencapsulated phytosterols for the formulation of functional foods: Scale up from laboratory to semi-technical production. Food Research International, 1-8 August.

de Vasconcelos, M. C. B. M., Bennett, R. N., Rosa, E. A. S., \& Ferreira-Cardoso, J. V. (2010). Composition of European chestnut (Castanea sativa Mill.) and association with health effects: Fresh and processed products. Journal of the Science of Food and Agriculture, 90(10), 1578-1589.

Wee, M. S. M., Nurhazwani, S., Tan, K. W. J., Goh, K. K. T., Sims, I. M., \& Matia-Merino, L. (2014). Complex coacervation of an arabinogalactan-protein extracted from the Meryta sinclarii tree (puka gum) and whey protein isolate. Food Hydrocolloids, 42, 130-138.

Yu, Y. T., Liu, L. N., Zhu, X. L., \& Kong, X. Z. (2012). Microencapsulation of dodecyl acetate by complex coacervation of whey protein with acacia gum and its release behavior. Chinese Chemical Letters, 23(7), 847-850. https://doi.org/10.1016/j.cclet. 2012.05.006.

Zhang, H. Y., Firempong, C. K., Wang, Y. W., Xu, W. Q., Wang, M. M., Cao, X., ... Xu, X. M. (2016). Ergosterol-loaded poly(lactide-co-glycolide) nanoparticles with enhanced in vitro antitumor activity and oral bioavailability. Acta Pharmacologica Sinica, 37(6), 834-844. 